\title{
FENOMENOLOGIA E RELIGIÃO: Ipseidade na acuidade da consciência
}

\author{
Phenomenology and religion: Selfhood in the acuity of consciousness
}

Roberto Pereira Veras ${ }^{1}$

\section{RESUMO}

Esta pesquisa cogita explicitar a fenomenologia como fundamento de "si mesmo" na ipseidade da elaboração dos aspectos implicados na capacidade de estruturação dos múltiplos conceitos de religião. Para tanto, iremos contextualizar os principais argumentos atuantes no método fenomenológico, cujo prisma historicista torna-se contraposto através do escopo religioso apresentado, sobretudo, pela escola italiana de história das religiões. Assim procedendo, aplicaremos o método hermenêutico-conceitual na ontologia fenomenológica apresentada por JeanPaul Sartre em sua obra $O$ ser e o Nada de 1943, para que possamos entender o conceito de consciência engajada contextualizada na perspectiva da religiosidade.

PALAVRAS-CHAVE: ipseidade, consciência, fenomenologia.

\begin{abstract}
This research is considering explain the phenomenology as the foundation of "himself" in ipseity the preparation of the aspects involved in structuring ability of multiple concepts of religion. Therefore, we will contextualize the main arguments working in the phenomenological method, which historicist perspective becomes opposed by the religious scope presented mainly by the Italian school of history of religions. In doing so, we will apply the hermeneutic conceptual method in phenomenological ontology by Jean-Paul Sartre in his work Being and Nothingness 1943, so we can understand the concept of consciousness engaged contextualized from the perspective of religion.
\end{abstract}

KEYWORDS: selfhood, consciousness, phenomenology.

\section{Introdução}

Consoante as complexidades labirínticas que encontramos nas pesquisas que envolvem o escopo fenomenológico em nosso trabalho não é diferente. Isso porque em linhas gerais, a necessidade de conclusões satisfatórias no campo fenomênico é condicionada a percepção do sujeito que, por sua vez estabelece uma pluralidade de perspectivas, na qual podemos compreender sobre a realidade dos objetos edificados no mundo exterior através de nossa consciência. Iremos percorrer na escola das religiões italianas e a origem da fenomenologia como metodologia de acesso ao campo prático da fé. Feito isso, o acesso do conjunto de fatores que influenciaram o desgaste do conhecimento metafísico clássico, assim como o circuito que propõe a abertura da consciência para o condicionamento do mundo enquanto plenitude. Em termos concretos, aspiramos de maneira

\footnotetext{
${ }^{1}$ Doutor em Ciências das Religiões pela UFPB. Professor de Filosofia do Instituto Federal do Acre - IFAC, Tarauacá, Acre. Membro da Associação Brasileira de Filosofia da Religião - ABFR. Líder do Núcleo de Estudos e Pesquisas sobre Artificial Intelligence - NEPAI/IFAC/CNPq.

RE V IS T A R E LEGEN S T H RÉ S K E I A - 2021 - U F P R
} 
ampla estabelecer uma condição sine qua non para o mecanismo fenomenológico atuar mesmo diante do modelo historiográfico da escola italiana de história das religiões, visto que se torna necessário um ponto de partida exclusivo para a elaboração daquilo que subjaz a realidade observada. Por outro lado, a incompatibilidade de conclusões sobre pluralidade de perspectivas é inegável. Assim procedendo, o modelo adotado por nossa pesquisa estabelece um diálogo com a escola italiana de história das religiões, isso porque é sobre a luz desta tradição que perceberemos o método comparativo, desse modo entenderemos que a religião se torna proveniente dos circuitos fatores históricos que se mostram na tradição ocidental.

Ademais, o método fenomenológico, antes de qualquer coisa é uma atividade filosófica. "Podemos dizer que a fenomenologia enquanto parte da filosofia mais criativa, o método mais arrojado para compreensão daquilo que possa ser manifestado, das impressões que figuram uma filosofia transcendental dentro do pensamento contemporâneo.” (OLIVEIRA, 2015, p. 12) Assim procedendo, a necessidade do diálogo com a tradição se mostra viável, isso porque a metafísica impulsiona a discrepância entre a elaboração concreta sobre a questão do sentido do Ser e o estatuto da realidade concreta. Nesse sentido, a religião é sustentada pelas verdades metafísicas, cuja elaboração é principalmente subjetiva. Nesse caso, uma das principais afirmações que conseguimos obter da tradição que a visão do mundo é apenas possível pela condição ontológica que fundamenta nosso espírito. Nessa perspectiva, funda-se a religião. A necessidade de uma base que consiga sustentar a realidade atemporal é introduzida entre mitos e ritos. Podemos tomar como exemplo os gregos, pois eles apresentam uma perspectiva religiosa que fundamenta sua ética desde o período clássico na figura de Homero e Hesíodo.

En todo caso, es en Grecia donde tenemos los primeros testimonios de una atención expresa al hecho religioso. Esta atención tiene tres tipos de manifestaciones. El primero aparece en el interior del mundo religioso mismo y constituye um simple desarrollo de la expresión "racional" del hecho religioso a través de los relatos míticos. En un momento determinado de la evolución de la religión politeísta, ésta sistematiza los mitos en los que se ha venido expresando su creencia en los dioses y a través de esa sistematización organiza sus múltiples manifestaciones en um panteón jerarquizado. En este sentido, Homero y Hesíodo, con sus mitologías y sus teogonias, constituirían la primera manifestación de la aplicación de la razón, ya de alguna manera sistematizadora, al hecho religioso. En ellos, como en las mitologías de todas las grandes culturas de la Antigüedad, más que los rudimentos de la ciencia de las religiones tenemos los precursores de la teología. Em efecto, más que describir o estudiar el hecho religioso, los poetas y los grandes "creadores" de los sistemas mitológicos se dedican a reflexionar sobre lo divino y a ordenar sus manifestaciones. (VELASCO, 1978, p.19) 
O campo abstrato de conceitos elaborados pelas religiões arcaicas se apresenta como a relação entre homem e mundo, assim sendo, o primeiro sempre como elemento condicionante da realidade vivenciada pela realidade do mundo. Aqui, primeiramente, a razão sistematiza as crenças apresentando respostas a cultura que outrora não se obtinha. A contribuição dos aspectos místicos para a evolução das sociedades é demasiadamente importante, pois é nessa configuração que o homem tem a probabilidade de ter acesso ao mundo enquanto realidade fenomênica, isto é o homem pode conseguir o acesso à vivência do real. "A revelação de um espaço sagrado permite que se obtenha um "ponto fixo”, possibilitando, portanto, a orientação na homogeneidade caótica, a “fundação do mundo”, o viver real.” (OTTO, 2007, p.12)

Todavia, a religiosidade está contida no fundamento tanto espacial quanto temporal, isso é notório. Assim, temos que verificar como a maneira fenomenológica atua e suas respectivas proposições que o sujeito se encontra inserido, uma vez que história e fenomenologia se complementam. "La relación de la fenomenología con la historia de las religiones y la atención, en el establecimiento de la estructura del hecho religioso, al elemento intencional han llevado a subrayar un último momento importante del método fenomenológico.” (VELASCO, 2006, p. 64) Segundo ele, os textos para o pesquisador das religiões são a forma pela qual o conhecimento é acolhido, sendo assim, a receptividade do leitor e aplicador do método faz a circulação das informações mais convincentes. É nesse aspecto que afirmamos a historicidade atrelada ao movimento fenomênico, cuja participação do sujeito é condição sui generis na elaboração das formas divinas.

Nesse ponto conseguimos perceber o reconhecimento do historicismo no processo de reconhecimento dos conteúdos adquiridos para análise do fenomenólogo da religião. Eis a parte entrelaçada das perspectivas que juntas condicionam a proposta da espécie científica do pesquisador. Podemos apresentar os avanços significativos que Raffaelle Pettazzoni (1883-1959), o titular da primeira cátedra em História das Religiões na Itália. Ele se consolidou com uma metodologia comparativista, através do enquadramento dos fatos religiosos, deste modo é possível a compreensão de seu procedimento de pesquisa. Isso porque, a religião não pode ser compreendida, para ele, fora das regras do estado e da política. Para Pettazzoni, a religião é fruto do processo histórico.

Toda religião é um produto histórico, culturalmente condicionado pelo contexto e, por sua vez, capaz de condicionar o próprio contexto em que opera. [...] O método de investigação das religiões assim concebidas se funda onde quer que seja no comparativismo histórico, o qual pressupõe a descoberta das analogias entre formações variadas como fase preliminar que permite, depois, definir com rigor a especificidade de cada fenômeno de cada contexto. O objetivo posterior do REVISTARELEGENSTHRÉSKEIA-2021-UFPR 
comparativismo histórico é a construção do processo de formação de um dado produto religioso ou de uma dada religião em seu conjunto. (MASSENZIO, 2005, p.150)

O historiador italiano ostenta um arquétipo bastante satisfatório para afirmar sua tese como, por exemplo: a religião monoteísta que, foi resultado do processo histórico, no qual a sua base se encontra no politeísmo ${ }^{2}$. É o que podemos chamar de percurso da evolução historiográfica no processo de desenvolvimento cultural das civilizações, no âmbito político, social e econômico.

A perspectiva histórico-comparativa de Pettazzoni nos aproxima de uma conclusão baseada em fatores históricos como uma variação de "Ser supremo" entre as varias bases culturais, proporcionando uma verdade mitológica e funcional como verdade para todos que acreditarem. Desse modo, o reflexo do monoteísmo primordial é descaracterizado por uma nova perspectiva, cujas bases estruturais estão voltadas para o etnológico e antropológico, isto é, o homem é detentor de sua realidade no determinado espaço que existe afim que possa misticamente se habituar aos costumes e crenças à sua maneira. Vejamos abaixo:

Em linhas gerais, podemos destacar algumas questões centrais para os principais representantes desta escola de estudos histórico-religiosos. Rafaelle Pettazoni não restringe o conceito de religião a uma determinada religião em sentido absoluto. Ao contrário, o conceito deve ser amplo o bastante para compreender, em sua universalidade, todas as formas particulares, operar no domínio da pluralidade das religiões e de ser chave de acesso aos sistemas religiosos. [...] Para Pettazzoni, toda religião seria um produto histórico, culturalmente condicionado pelo contexto e capaz de condicionar o próprio contexto. Há uma dimensão comum que permite compreender as diferenças entre os sistemas religiosos. Estas diferenças englobam diversidades econômicas, políticas e sociais nos diferentes âmbitos históricos. A pluralidade das religiões remeteria à pluralidade das histórias e vice-versa. A metodologia e teoria sobre em que âmbito específico se situa a religião fica assim formulada. (SILVA, 2011, p. 228)

Para o pensador italiano a religião não está apenas fundamentada em uma unidade. Nesse aspecto o método do historiador italiano é a condição do estudo comparado para que o fenômeno consiga ser analisado em suas próprias categorias. Assim todas as religiões são provenientes de um contexto, no qual a realidade é a perspectiva cultural. Feito isso, o caráter hermenêutico apresenta-

\footnotetext{
${ }^{2}$ Hume rejeita a concepção das religiões politeístas passarem a ser monoteístas através de uma linha cronologicamente correta. Isso porque, o filósofo inglês acredita que nesse oscilar irracional do flux and reflux, existe a possibilidade de alteração dos estados das religiões por meio de necessidades. Para o filósofo inglês, a religião predominante do passado era o politeísmo com um intuito de classificar os elementos da natureza e práticas diversas à uma divindade hierarquicamente mítica. "É um fato incontestável que aproximadamente 1700 atrás [contexto histórico de David Hume] toda a humanidade era politeísta. Os princípios incertos e céticos de alguns filósofos, ou o monoteísmo, que não era inteiramente puro, de uma ou duas nações, [...]." Cf. HUME, D. História natural da religião. Tradução de Jaimir Conte. São Paulo: Editora UNESP, 2005, p. 23 [grifo nosso].
} 
se como a conectividade entre o sagrado e o profano, pois é na interposição de dados imediatos da realidade fenomênica que o modelo historicista consegue atuar. “[...] os estudos históricosreligiosos, partem da necessidade de ressaltar, antes de mais nada, a historicidade dos fatos religiosos enquanto produtos culturais, redutíveis em sua totalidade à razão histórica.” (AGNOLIN, 2013, p.67) Podemos afirmar que a tradição italiana consegue aprimorar suas pesquisas através do método histórico-religioso. Assim, o diálogo com pesquisadores consagrados [Max Müller (18231900)], mostra que o trabalho contextualizado na perspectiva histórica é uma contribuição bastante relevante no estudo das religiões. Pois, a relação entre o produto sagrado com a totalização histórica é uma análise mais própria da relação entre homem e universo.

Adiante, percebemos que existe uma problemática bastante justa entre as formas de acesso no campo das investigações religiosas. Isso porque o modelo fenomenológico é discrepante à luz da forma historicizada, pois ambas procuram pontos de partida diferentes, sob a necessidade de respostas para o campo das religiões como podemos ver a seguir.

Tendo em vista tudo isso, portanto, na medida em que a Fenomenologia se constitui enquanto uma teleologia, pressupostamente científica - que no final de seu percurso reencontra as origens inscritas em seus pressupostos iniciais -, a História das Religiões se configura enquanto, propriamente uma ciência histórica. Daí o fato de que, ao objetivismo ontológico da sacralidade da primeira perspectiva, a segunda lhe contrapõe, efetivamente, o percurso obrigatório de uma história das relações entre civilizações: negando a perspectiva objetiva $e$ totalitária da Fenomenologia para tornar-se culturalmente subjetiva. (AGNOLIN, 2013, p.67 [grifo do autor])

Nesse sentido, o impasse entre a fenomenologia e a história como métodos para a compreensão das manifestações acabam entrando em conflito nesse ponto, isso ocorre devido a meios divergentes a fins comuns. O modo fenomenológico aqui entendido como a forma clássica trata da objetivação da religião. Nesse modo, a religião é tida como única em sua origem que, por sua vez designa outras vertentes, nesse caso a religião seria criação do próprio homem religioso. Em contraposição, a forma historicista atua sobre a desobjetivação da religião, isto é, uma busca entender o sagrado e o profano pelo genómenon e não pelo fainómenon, isso porque a história mostra realidade dos fatos em relação a temporalidade.

[...] para cumprir sua função, isto é, a formação de uma consciência históricoreligiosa, longe de restringir o conceito de uma determinada religião assumida como a religião em sentido absoluto, deve, ao contrário, postular um conceito bastante largo de religião que compreenda na sua universalidade todas as formas particulares, resolvendo-se concretamente nisso a própria universalidade da 
investigação histórico-religiosa, ao invés de uma quimérica história universal das religiões. (PETAZZONI apud SILVA, 2011, p. 228).

Em linhas gerais, a proposta do historiador italiano é que as múltiplas formas de religiões existentes na sociedade propõem diversos fatores que contribuíram para seu desenvolvimento. Isso porque, ante as modificações econômicas, políticas e sociais que a civilização perpassa a sociedades avançam sua cultura e modo de pensar, feito isso a história universal das religiões vai perdendo foco. Mas, para que isso não ocorra existem pesquisas fundamentadas no arcabouço historiográfico, nas quais, apreendem a realidade do passado, dialogando com o presente, fazendo assim uma "hermenêutica religiosa” para ordenação dos fatores habituais. Essa formação do pensamento histórico para uma concepção ativa na realidade das religiões é um caminho a ser pensado, nesse aspecto se torna válido até que outra tenha sido sustentada. Destarte, sabemos que a tradição da escola italiana preserva seu valor através das bases históricas, porém necessitam apresentar-se em algum momento da existência, pois todos os fatos históricos são atos e fatos reais da ser-no-mundo. Iremos analisar como se fundamenta o trajeto das realidades no mundo enquanto fenômenos que, por sua vez se tornam história ao decorrer do tempo.

Havíamos mencionado anteriormente que nossa proposta é estabelecer um contraponto entre o pensamento histórico e fenomenológico na fundamentação do conceito de religião(ões); assim, é notório que investigamos as bases conceituais que provocaram tamanha importância na concepção filosófica e científica na contemporaneidade.

\section{A fenomenologia como fundamento de "si-mesma"}

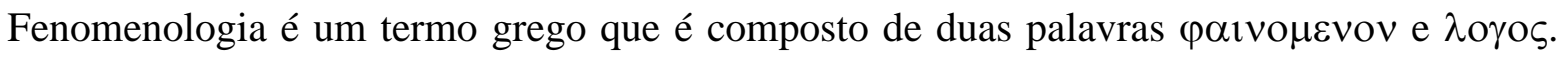
Todavia, é interpretada como mostrar aquilo que se revela, trazer a luz das coisas que se revelam. “A palavra fenomenologia exprime uma máxima que se pode formular a expressão: "as coisas mesmas!” - por ocasião às construções soltas no ar, às descobertas acidentais à admissão de conceitos só aparentemente, por oposições às pseudoquestões [...].” (HEIDEGGER, 2005 p.57) Ademais, começamos a compreender que o mundo é apresentado de maneira desordenada para o sujeito que, através do método fenomenológico apreende de maneira pura as coisas, assim formulando uma condição de possibilidade em torno da problemática do conhecimento.

A fenomenologia adquiriu estabilidade como ponto de partida de nossas investigações. Isso porque, podemos analisar a estrutura metodológica de Husserl (1859-1938) sobre o conceito de intencionalidade da consciência que o filósofo alemão utiliza para compreender como é concebido o conhecimento na relação entre sujeito e objeto. "Husserl desencadeia um processo de 
fundamentação absolutamente rigoroso, a partir do qual sucedem-se exigências cada vez mais radicais até atingirmos a evidência apodítica.” (ZITKOSKI, 1994, p. 17)

O método de Husserl, por sua vez, não aparenta haver o mesmo posicionamento cartesiano, no qual, a afinidade entre sujeito-objeto estaria diretamente ligada a uma hierarquia ou determinação independente do próprio sujeito que o projeta. Pelo contrário, na intencionalidade o sujeito se correlaciona com o objeto, essa relação vai se estabelecendo o conhecimento fenomênico pode ser compreendido. Isso porque, existem várias formas de conhecer as coisas, a princípio, pela relação consciência-mundo.

Para explicitarmos melhor essa metodologia, devemos recuperar a trajetória que René Descartes (1596-1650) percorreu para tentarmos abarcar quais as diferenças e críticas entre as diversas afirmações sobre o conhecimento. Primeiramente, o filósofo francês apresenta seu modelo filosófico baseado na desconstrução de todo conhecimento antes falho, no qual o tenham enganado pelo menos uma vez. Esses conhecimentos não são tidos como seguros. Para tanto, o pensamento cartesiano consegue após essa dúvida hiperbólica apresentar algo que não pode ser duvidado, e que pode ser caracterizado como primeira instância para uma nova formulação do conhecimento do mundo físico. O Eu pensante (cogito).

Arquimedes, para tirar o globo terrestre de seu lugar e transportá-lo para outra parte, não pedia nada mais exceto um ponto fixo e seguro. Assim, terei o direito de conceber altas esperanças, se for bastante feliz para encontrar somente uma coisa que seja certa e indubitável [cogito]. [...] Eu sou, eu existo: isto é certo; mas por quanto tempo? A saber, por todo o tempo em que eu penso; pois poderia, talvez, ocorrer que, se eu deixasse de pensar, deixaria ao mesmo tempo de ser ou existir [...] Mas o que sou eu portanto? Uma coisa que pensa. Que é uma coisa que pensa? É uma coisa que duvida que concebe, que afirma, que nega, que quer, que imagina também e que sente. (DESCARTES, 1983, p. 91-94 [grifo nosso])

Para Husserl, o erro de Descartes foi ter concebido uma substância pensante (ego) que ordenaria com superioridade a produção de conhecimento. "Pois ao conceber o ego como uma substância que é o ponto de partida para todo conhecimento, Descartes desconsiderou toda a relação do eu com os objetos, que é, na verdade, a fonte de todo conhecimento e raciocínio.” (SILVA, 2009, p.46 [grifo autor]) Não tendo outra forma de afirmação do mundo, Descartes parte sustentar a veracidade de suas afirmações acionando subterfúgios como a ideia de Deus e a segurança nas matemáticas como critério de validade para as certezas sobre o mundo. Assim, detectado o problema do conhecimento proposta por Descartes, podemos seguir explicitando como acontece nas contraposições no pensamento de Husserl, que logo em seguida proporcionaram grande influência na concepção fenomenológica de conhecimento das coisas para Sartre. 
Para Husserl, a fenomenologia consiste na melhor forma de investigação dos fenômenos para a consciência. Isso porque a consciência enquanto um “fora das coisas” possui um relacionamento com o mundo. Esse dirigir-se para fora de si proporciona uma atividade constante de intencionalização da consciência. “A intencionalidade é aquilo que caracteriza a consciência no sentido forte, e que justifica ao mesmo tempo designar todo o fluxo de vivido como fluxo de consciência e como unidade de uma única consciência.” (HUSSERL, 2006, p. 190 [grifo do autor]). Dessa forma, na consciência "sem conteúdo” não há um dentro, o relacionamento com as coisas implica na abertura de novas possibilidades de conhecimento. Esse processo nunca se esgota, uma vez que a intenção ocorre de forma imanente de maneira ininterrupta.

A forma fundamental desta síntese universal, que torna possível todas as outras formas de síntese da consciência, é a consciência imanente do tempo. Correlativamente corresponde-lhe a própria duração imanente, em virtude da qual todos os estados do eu, acessíveis à reflexão, se devem apresentar como ordenados no tempo - simultâneos ou sucessivos, - no seio do horizonte infinito e permanente no próprio tempo imanente. (HUSSERL, 2006, p. 60)

Com isso, o método fenomenológico husserliano é uma nova perspectiva de compreensão da realidade, isso porque, antes os objetos eram tratados como substâncias; - com Husserl, torna-se um dirigir-se para fora de si, a busca com a consciência intencionada revoluciona o caráter sistemático do conhecimento. Dessa maneira a busca para se conhecer alguma coisa não parte da superioridade de nenhum dos polos. (sujeito-objeto) “A consciência está sempre direcionada para um objeto e o objeto só pode ser definido em relação a uma consciência”. (SILVA, 2009, p 52)

Na perspectiva sartriana, o método da fenomenologia estabelece uma busca não apenas do conhecimento que poderá ser oriundo da consciência, antes disso, o filósofo francês busca examinar a estrutura ontológica do ser em sua correlação com o sujeito. Isso porque, as filosofias que adotam um modelo de interioridade são criticadas pelo pensamento sartreano, na medida em que desejo ser pleno; portanto, tenho desdém da perfeição divina, almejando sempre ser Deus. Para Sartre, isso se torna inviável, uma vez que, o sujeito não pode ser falta e plenitude ao mesmo tempo. "Basta que o Eu [Moi] seja contemporâneo do mundo e que a dualidade sujeito-objeto, que é puramente ontológica, desapareça definitivamente das preocupações filosóficas.” (SARTRE, 1994, p.83[grifo do autor])

Dessa maneira, o criticismo kantiano também é criticado na filosofia de Sartre, isso porque, em Kant existe um pressuposto metafísico que consegue ordenar os fenômenos naturais e por meio das faculdades do conhecimento. Em outras palavras, a perspectiva kantiana é criticada, 
na medida em que o sujeito transcendental apresenta uma organizada estrutura cognitiva a priori, cujo todo mundo físico se transforma em conhecimento.

A coisa, tal como se pode compreender graças às faculdades que o homem possui, é a coisa na medida em que me aparece; é, dada pelas formas da sensibilidade - o espaço e o tempo - ou seja, é o fenômeno. Igualmente o mundo em que vivemos e nos é acessível é o que aparece graças às nossas faculdades do conhecimento. Do mesmo modo o mundo científico, que surge pela contribuição do sujeito, é fenomênico. Ao lado de fenômeno utiliza Kant o conceito de númeno que significa a coisa não conhecida, pois só se conhece na medida em que nos aparece, mas pensada. A coisa que não está submetida às condições do conhecimento é a coisa em si. (KANT, 2001, p. 12-13)

A proposta filosófica apresentada por Sartre intenta compreender a existência do homem inserido no mundo. Dessa forma, o filósofo francês propõe uma ontologia fenomenológica, isto é, ele tenta descrever o homem a partir de uma interpretação filosófica dos fenômenos. Isso porque nada pode ser conhecido como fato isolado da consciência, deve-se existir uma relação entre o sujeito e objeto. Para o filósofo francês, pensar o homem é desenvolve o estudo da consciência, feito isso Sartre consegue constitui uma ontologia baseada no método fenomenológico apresentado por Husserl que permite superar as dicotomias do tempo moderno no processo do conhecimento.

Assim procedendo, Sartre não concorda que o conhecimento é proporcionado por um conjunto de faculdades interiores que direcionam o sujeito como ponto de partida fundante e principal na relação sujeito-objeto. Antes disso, ele percebe que a consciência é dirigir-se lançar-se de para fora de si. "Toda consciência é consciência de alguma coisa.” “A consciência e o mundo são dados de uma só vez: por essência exterior à consciência, o mundo é, por essência, relativo a ela.” (SARTRE, 2011, p.56)

Sendo assim, toda consciência se lança para fora de si, em termos sartrianos torna-se a Serpara-si, isto é, nada. Ele tem leveza, suavidade, falta e busca se completar a todo instante de maneira atemporal. Por sua vez, o ser-em-si é pleno, possui densidade está completo e sem faltas. Segundo Sartre, a consciência também possui um cogito pré-reflexivo que mesmo antes de começar o dirigir-se ela toma consciência de alguma coisa mesmo de maneira não apresentável, ela é uma forma de consciência não posicionada que auxilia no ato da reflexão. “Assim, não há primazia da reflexão sobre a consciência refletida esta não é revelada a si por ela. Ao contrário, a consciência não refletida torna possível a reflexão: existe um cogito pré-reflexivo que é condição do cogito cartesiano.” (SARTRE, 2012, p. 24)

A consciência se lança ela buscando o mundo e nesse exercício podemos afirmar que todo lançar-se tem um objetivo, o projetar-se para outra perspectiva, assim podendo criar uma nova 
realidade humana. Para Sartre essa falta no dirigir-se da consciência acontece pela frustração da limitação de plenitude que todo homem possui. Essa impossibilidade causa uma “paixão inútil” por não conseguir se completar enquanto Ser- em-si -, Ser-para-si.

Mas isso significa, com efeito, que o homem é precisamente um Ser em si faltado. Em consequência, o Ser completo que o assedia constantemente - e com o qual ele tende a querer se amalgamar - é precisamente o si- mesmo enquanto Em-si. Eis, então, o desejo ontológico fundamental do Para- si: ser todo inteiro plenitude de Ser e todo inteiro consciência, ser a síntese da "pedra" e de "Deus"; enfim, todo coisa e todo consciência, sem a menor fissura interna, mas, ainda assim, sendo transcendência. Desse modo, todos os projetos originais concretos da "realidade humana" são elaborados a partir de uma frustração comum: a de não ser Deus. Todo Para-si projeta ser Deus e, naturalmente, fracassa: a combinação da transparência da consciência com a opacidade do Em-si equivaleria a tornar o Parasi um ens causa sui. Destarte, diz-nos Sartre, a realidade humana não é senão uma “paixão inútil” (YAZBEK, 2006, p. 45)

Assim, a consciência enquanto (nada) sempre busca sua completude. A falta é sua característica fundamental, pois com isso ela não se confunde com o mundo. “A sua condição intencional revelou-nos que ela implica em outro ser que não si mesma. Encontramos aí o ser transfenomenal dos fenômenos.” (SASS, 2002, p. 16) Dessa forma, Sartre por meio do mecanismo da intencionalidade consegue desenvolver condições de possibilidades para a fuga da determinação histórico-filosófica que propõem um primado do sujeito em relação aos objetos (mundo-natureza). O acesso ao Ser das coisas somente é possível pelo mecanismo da fenomenologia ontológica que tenta compreender os possíveis estatutos ontológicos que as coisas podem apresentar. Isso acontece não necessariamente enquanto conhecimento, mas como reflexão da correlação entre sujeito e objeto, ambos no mesmo grau de objetivação existencial. “A ontologia fenomenológica descreve a estrutura do ser-aí como paixão inútil, como desejo de reconciliar o irreconciliável: a união do serpara-si com o ser-em-si.” (JÚNIOR, 2006, p.33)

Essas duas perspectivas necessitam de uma sintonia para que a correlação aconteça. Cabe à intencionalidade da consciência ordenar seu direcionar-se para outro que não seja ela mesma. Assim o “nada” da consciência será o viés pelo qual o homem conseguirá ao menos estabelecer complementos de compreensão da realidade mesmo de maneira vazia e obscura na maioria das vezes.

É a intencionalidade radical da consciência, pensada como nada e como atividade de nadificação, como pura transcendência em direção ao em-si, o qual, assim nadificado, se torna fenomenologicamente presente como mundo. É essa intencionalidade nadificadora que estabelece a relação, uma vez que o em-si se 
basta, ele é pura e simplesmente, não precisa do para-si para ser. (MÜLLER, 2006, p.18)

Afirmamos que a intencionalidade proporcionou uma ruptura contra as perspectivas de conhecimento acerca do mundo, assim como, a descrição ontológica das coisas pelo núcleo fenomenológico. A nadificação, para Sartre, surge como uma necessidade de complementação da sua existência. Entendemos que o conceito de consciência sartriana direcionar-se para uma busca, dessa forma, a relação com o mundo fica estabelecida pela construção da intencionalidade. Este, por sua vez apresenta certo grau de definição ante os múltiplos objetos existentes no mundo. Fazendo isto, o homem consegue o significado e a essência de cada objeto, não obstante, de sua própria significância. A consciência tem a capacidade de sintetizar os objetos pensados nas unidades e na temporalidade. Na medida em que toda consciência é consciência de algo, o homem consegue se libertar e tentar se completar; uma vez que, isso não consegue ser feito, esse movimento de libertar-se e projetar-se, quando não concluído com êxito torna-se atormentador.

Observamos que a fenomenologia é um instrumento metodológico empregado pela filosofia sartriana, e que tem como principal objetivo visitar o mundo constantemente, isto é, tentar voltar às coisas mesmas. Esse método filosófico se torna conhecido com Husserl através de sua abordagem acerca do fenômeno. O voltar às coisas mesmas proporciona no sujeito múltiplas situações vividas constantemente. A consciência é a relação com o fora, pois ela não possui um dentro, ela é constante movimento. "Voltar às coisas mesmas significa o retorno daquilo que nos aparece como algo experimentado, vivido, conhecido, mas que não é dado como algo existente no mundo.” (SILVA, 2009, p.47)

Isso porque toda consciência é consciência de alguma coisa. É o que Husserl afirma sobre se relacionar-se com o mundo, isto é, apenas uma das formas de conhecer o mundo pode ser constatada pela explosão em direção a alguma coisa. A nossa relação com o mundo é todo momento externa à consciência. Assim procedendo, podemos afirmar que toda consciência é interessada. Esse movimento contínuo de explodir-se faz com que se torne impossível entrarmos em nossa própria consciência, uma vez que ela não possui um interior, pois sempre está exterior a si mesma.

Ser é explodir para dentro do mundo, é partir de um nada de mundo e de consciência para subitamente explodir-como-consciência-no-mundo. Se a consciência tenta se reconstituir, coincidir enfim consigo mesma, então imediatamente, a portas fechadas, se aniquilará. Essa necessidade da consciência de existir como consciência de outra coisa que não ela mesma, Husserl chama de “intencionalidade”. (SARTRE, 2011, p. 57) 
A consciência tem a intencionalidade como elemento irredutível, embora ela não possua um “conteúdo”, ou seja, ela busca constantemente se completar, porém nunca alcança sua plenitude. Também é perceptível que o movimento no qual a consciência se constitui em hipótese alguma pode se coincidir consigo mesma, isso porque ela não possui um dentro para se autorrefletir. Assim procedendo, na ontologia proposta por Sartre podemos descrever a consciência como uma espontaneidade pura, isto é, ela pode ser por si mesma independente das coisas do mundo, a saber, os outros fenômenos.

Essa estrutura humana (consciência) é um distanciamento que está em constante inadequada com o mundo, na medida em que ela busca se completar consigo mesma ela tende a se afirmar como nadificar. Isso porque quando ocorre seu lançar-se a consciência tem interesse de se completar.

A consciência é o vazio transparente que se alimenta da sua intencionalidade, ou seja, a sua vida está em perpétua ligação com algo que ela não é. Essa diferença existente entre a consciência e o objeto é perpassada por uma fissura intraconsciencial, como distância ideal na imanência do sujeito em relação a ele mesmo. Essa distância é verificada na estrutura primordial do Para-si enquanto presença a si como consciência (de) si, cujo fundamento está no próprio nada. A distância ideal que separa a consciência de si como modalidade de relação somente poderia encontrar fulcro no vazio que ela mesma impõe. (CASTRO, 2005 p. 50)

O vazio da consciência é uma concepção que podemos estabelecer em contraposição ao cogito cartesiano. Isso porque, a metafísica estabelecida nas Meditações tinha como principal objetivo provar a existência de Deus, cujo mesmo havia implantado em nossa alma conteúdos inatos que seriam possíveis de conhecer tanto Deus, quanto o mundo.

Esse dualismo que embaraça a filosofia também pode ser encontrado no pensamento kantiano. Na medida em que o sujeito antes de existir já possui estruturas e condições de possibilidade para o acesso das coisas (fenômenos). A existência do eu transcendental caracteriza-se como unidade apriorística que possui faculdades do conhecimento, cujas mesmas são inteiramente pré-estabelecidas ao sujeito no processo de conhecimento. Processo esse que Sartre não aceita como critério filosófico. Para Sartre, não podemos conhecer as coisas, conseguimos apenas descrevê-las no processo de relação entre consciência e mundo. Isso porque nem toda consciência é conhecimento, existem consciências afetivas que não se enquadram nesse processo de conhecer. Dessa maneira conseguimos compreender o método fenomenológico como recurso para o estudo da consciência.

Sartre, em sua obra $O$ existencialismo é um humanismo reforça nossa afirmação no seguinte momento: 
Se concebermos Deus como criador, Ele será na maior parte das vezes, semelhante a um artífice superior; e qualquer que seja a doutrina que consideremos, quer se trate a doutrina na como a de Descartes ou como a de Leibniz, admitimos sempre que a vontade segue mais ou menos o entendimento ou, pelo menos, o acompanha, e que Deus, quando cria, sabe precisamente o que está criando. (SARTRE, 2012, p.24)

Do mesmo modo:

Esta ideia [a essência precede a existência] pode ser encontrada praticamente em todo lugar: encontramo-la em Diderot, em Voltaire e até mesmo em Kant. O homem seria possuidor de uma natureza humana; esta natureza humana, que é o conceito humano, se encontraria em todos os homens, o que significa que cada homem é um exemplo particular de um conceito universal, o homem; dessa universalidade resulta que, em Kant o homem da selva, o homem da natureza e o burguês, estão todos encaixados na mesma definição e possuem as mesmas qualidades básicas. Assim, mais uma vez, a essência do homem precede essa existência histórica com que nos deparamos na natureza. (SARTRE, 2012, p.25 [grifo nosso])

Através desse apontamento sobre as questões que envolvem a concepção filosófica dos modernos, compreendemos que Sartre articula seu pensamento sob uma crítica direcionada à interioridade. Feito isso, o filósofo francês busca apresentar uma filosofia baseada no vazio da consciência, isto é, na nadificação de si mesmo. Segundo Sartre, não possuímos uma essência implantada por Deus. Antes de tudo o homem é pura atividade, esse ininterrupto movimento da consciência proporciona uma constante movimentação do homem.

Com isso podemos pensar que o dualismo foi superado pelo monismo do fenômeno? A princípio, isso pode ser possível através do estudo da consciência. Esse conteúdo apresentado nas filosofias modernas são concepções epistemológicas que sempre parte de uma perspectiva de compreensão da realidade estabelecendo uma relação entre sujeito-objeto. Diferentemente de Sartre que não busca conhecer os fenômenos.

Desse modo, constatamos na filosofia sartriana que o conceito de consciência é diferentemente apresentado do modelo idealista. Uma vez que, para os modernos, sobretudo (Descartes e Kant) a dualidade entre sujeito-objeto era constantemente discutida sob uma perspectiva aparentemente hierarquizada do sujeito na estruturação epistemológica. A filosofia moderna se caracterizou em reduzir o mundo em pressuposto que seriam condição necessária de acesso a realidades metafísicas e epistemológicas de compreensão das coisas. Em Sartre, esse método filosófico de conhecer as coisas é criticado. Isso porque não conhecemos as coisas como os modernos afirmavam. Para Sartre a ontologia é o ponto fundamental de compreender a descrição do REVISTARELEGENSTHRÉSKEIA-2021-UFPR 
mundo, sobretudo do homem. A consciência era tratada como uma substância para os modernos. Em Sartre, a consciência é um dirigir-se para fora de si.

Toda consciência, mostrou Husserl, é consciência de alguma coisa. Significa que não há consciência que não seja posicionamento de um objeto transcendente, ou, se preferimos, que a consciência não tem "conteúdo". E preciso renunciar a esses "dados" neutros que, conforme o sistema de referência escolhido, poderiam constituir-se em "mundo” ou em "psíquico”. Uma mesa não está na consciência, sequer a título de representação. Uma mesa está no espaço junto à janela etc. A existência da mesa, de fato é um centro de opacidade para a consciência; seria necessário um processo infinito para inventariar o conteúdo total de uma coisa. Introduzir essa opacidade na consciência seria levar ao infinito o inventário que a consciência pode fazer de si, convertê-la em coisa e recusar o cogito. O primeiro passo de uma filosofia deve ser, portanto, expulsar as coisas da consciência e restabelecer a verdadeira relação entre esta e o mundo, a saber, a consciência como consciência posicional do mundo. (SARTRE, 2011, p.22)

Indubitavelmente, fica explicito que na obra O Ser e o Nada que devemos esvaziar nossa consciência para que possamos constituir uma verificação ontológica, por meio da fenomenologia sem dualismos ou vestígios de uma epistemologia tradicional. Isso porque o mundo não está dentro de nossa consciência, para Sartre a consciência se posiciona diante do mundo e se relaciona ininterruptamente nem sempre buscando conhecimento.

Na filosofia sartriana, a consciência antes de tudo não possui um dentro, ela é uma estrutura que se relaciona com as coisas; isto é, ela não é um conhecimento, bem como o conhecimento não produz a consciência, antes disto a consciência existe enquanto condição de conhecer o transfenomenal. A consciência é uma abertura para o mundo, portanto ela é um lançarse para e total abertura para a se relacionar-se com os fenômenos. Essa estrutura humana (consciência) é um distanciamento que está inadequada com o mundo, na medida em que ela busca se completar consigo mesma ela tende a se afirmar como nadificação.

Mesmo com as críticas voltadas ao cogito cartesiano, o pensamento sartriano concorda com a existência de um fio condutor que inexoravelmente pode ser apontado como recurso filosófico para a estruturação filosófica do estudo da consciência. "Não é possível existir outra verdade, como ponto de partida, do que essa: penso, logo existo, é a verdade absoluta da consciência que apreende a si mesma.” (SARTRE, 2012, p. 46) Podemos perceber que a consciência para ser consciência tem que voltar a si mesma. Dessa forma, Sartre mostra o conceito do cogito pré-reflexivo de como ter consciência de conhecer o conhecido. Existe a consciência posicional (refletida), porém anteriormente a consciência reflexiva atua espontaneamente como, por exemplo: a contagem de cigarros que ocorre enquanto cogito pré-reflexivo. Desse modo, podemos 
observar que para Sartre antes de uma teoria do conhecimento existe uma ontologia. Essa ontologia busca descrever o Ser na sua multiplicidade.

Junto a fenomenologia, Sartre apreende a noção de intencionalidade da consciência na proposta filosófica de renovação e compreensão do homem [religião]. A intenção é algo inerente à consciência. Isso porque toda consciência necessita existir como consciência de outra coisa que não seja ela mesma. Assim procedendo, podemos caracterizar a intencionalidade como uma característica que atua constantemente entre a relação de consciência e mundo. Ao mesmo tempo em que a intencionalidade atua constantemente o vazio a consciência também se estabelece. Isso porque o lançar intencionado da consciência necessariamente busca se completar no mundo. Essa carência de completude se caracteriza por voltar a si mesma, uma vez que ela somente poderá ser consciência porque não é nada. Adiante, o conceito de intencionalidade mostra quanto a consciência é vazia. O Para-si busca constantemente plenitude, mas o que caracteriza sua existência é conhecer a si mesmo como nada. Por sua vez, o Em-si enquanto perfeição está aberto a múltiplas possibilidades de relacionamento com a consciência.

Mas a possibilidade também pode nos aparecer como estrutura ontológica do real: aí, então, pertence a certos seres como sua possibilidade, é a possibilidade que eles são, que têm de ser. Nesse caso o ser mantém no ser suas próprias possibilidades, é o fundamento dessas possibilidades, e, assim, não cabe de derivar de sua possibilidade a necessidade do ser. Em uma palavra: Deus, se existe, é contingente. (SARTRE, 2012, p. 131 [grifo nosso])

Podemos afirmar que o método da fenomenologia proporcionou grandes avanços na filosofia proposta por Sartre. Filosofia esta que buscou todo momento fazer um estudo da descrição consciência de maneira ontológica. A consciência enquanto abertura e atividade se estabeleceu enquanto ponto de partida para a descrição do Ser. O vazio da consciência agora em Sartre sintetiza uma filosofia que não se confunde com o mundo. Através da ontologia fenomenológica podemos reaprender a ver o mundo.

Desse modo, conseguiremos entender como o aspecto religioso é verificado no escopo filosófico apresentado em seu pensamento. Isso porque, a religião, mesmo não sendo um assunto direcionado para suas conjecturas, a proposta do existencialismo pressupõe uma negação a problemas de ímpeto irreal, isto é, afirmação de questões transcendentes. Ademais, o projeto sartriano é perceptível, pois o caráter de imposição à liberdade que a religião predomina é, por outro lado, o desimpedimento nas ações ocasionadas pelo sujeito demonstra que Deus não poderá existir, uma vez que seria uma falsa liberdade. "A ideia é que, se Deus existe, o homem não é livre.” (OLIVEIRA, 2013, p. 56) Para Sartre, estamos condenados à liberdade. 


\section{Considerações finais}

Diante do paradoxo da existência podemos compreender que no uso da fenomenologia para investigação das religiões torna-se viável, isso porque a manifestação do fenômeno se torna perceptível através deste recurso metodológico. A existência ou não de preceitos metafísicos [Deus] é questionada durante toda história do pensamento humano, aqui não conseguiríamos responder. Todavia, a religião juntamente com a fenomenologia mostra um Sartre que se preocupa com a realidade do homem enquanto Ser-no-Mundo buscando entender as coisas. A religião não é uma tarefa do engajamento filosófico, mas podemos exemplificar esse aspecto por causa das necessidades que envolvem seus problemas e discursos. Sendo assim, o contraponto hermenêutico que almejamos constituir nas bases conceituais desse trabalho são de caráter híbrido, uma vez que a história é um conjunto de fatores no quais relatos apresentam a propagação de afirmações. Ademais, o processo fenomenológico atua na realidade implícita do parâmetro da realidade prática, diferentemente do historicismo.

A condição que possibilita o homem de olhar o fenômeno religioso é a consciência. A ipseidade de existir como fator singular estabelece uma condição no âmbito investigativo, ou seja, na busca das representações religiosas. Todavia, podemos afirmar que a partir do próprio individualismo consciente a possibilidade de acesso juntamente com o método fenomenológico aos caracteres do mundo, especificamente aos atributos religiosos torna-se aceitável. Porém, é necessário entender que a necessidade de estar situado em algum tempo e espaço também é fator predominante no caráter investigativo fenomênico. O aspecto que tentamos mostrar com a exemplificação do processo sartriano é uma propedêutica daquilo que podemos inferir sobre o prisma das religiões. A busca por informações significativas que outrora eram modeladas pela crença, ademais compreendemos como processo de investigação de uma consciência que atua no mundo [religioso].

Notadamente a perspectiva implícita na elaboração destes argumentos se encontra em pilares filosóficos. Desse modo, o mecanismo que primordialmente conseguimos fundamentar como solidificação conceitual para nossas bases é a fenomenologia como discrepância inicial ao processo histórico das religiões. Em outros termos mais específicos, o caráter religioso somente é religião porque existe uma cadeia de resultados plausíveis para que isso ocorra. A individualidade juntamente com a metodologia fenomenológica não poderia atuar senão no mundo prático. Porém, através dessa manobra a história consegue ser feita deixando, assim, uma necessidade de realização momentânea no processo religioso. 
Dessa forma, conseguimos perceber que a fenomenologia e a religião precisam de acesso à cultura, ao ponto de que o historiador precisa de material empírico para determinar o avanço de suas conclusões. Torna-se impossível isolar uma cultura determinada, ao passo que o próprio conceito de religião é fundamentado através de uma pluralidade de fatores distintos.

Nosso exemplo sartriano é coerente ao ponto de afirmarmos um índice na compreensão da individualidade da consciência, isso porque é notório percebermos a fragilidade dos sujeitos que absorvem uma verdade como universal e plena. O processo fenomenológico buscando o direcionamento de consciência que se lança intencionalmente no mundo, que possa preenchê-la, podendo ser resultado também na fundamentação do aspecto divino. Sartre não propõe uma análise detalhada sobre a questão religiosa, mas intrinsecamente suas obras literárias, teatrais e romances introduzem reflexos que desembocam no problema da religiosidade. No existencialismo conseguimos entender a proposta da existência não como dádiva suprema, mas como um lançar-se no mundo, portanto a liberdade do homem é a negação do sagrado. Aqui entendemos que a religião se vincula a ser o próprio sujeito que detêm convicções de suas crenças, desse modo a influência de condicionamentos divergentes a suas atividades religiosas não podem influenciar sua realidade.

O que podemos afirmar é que o método fenomenológico por mais que procure os dados imediatos através dos resultados indubitáveis na busca da verdadeira fundamentação do mundo a proposta de realidade é necessariamente uma parte do sujeito atuante, com sua própria consciência, na elaboração dos aspectos mais concretos das coisas, em especial, o fenômeno religioso, nosso objeto de pesquisa.

Em suma, o ponto de partida que conseguimos entender, particularmente, no campo religioso é produzido pelo sujeito que analisa conforme o método mais conveniente para o êxito em sua pesquisa. Isso porque, a princípio, o modelo fenomenológico necessita de condições apriorísticas para o desenvolvimento da conceitualização daquilo que é religioso. Por outro lado, não é possível desvincular a tradição religiosa de seu passado histórico formando assim uma condição homogênea que atua numa faceta de duplicidade. Em outras palavras, a necessidade do pesquisador em perceber os dois tipos metodológicos para o avanço da história e filosofia da religião é condição indispensável, pois é no próprio pesquisador que parte o olhar direcionado para a estrutura conceitual do passado, porém deixando abertura no que diz respeito à possibilidade de expandir o olhar para o fenomênico das religiões em múltiplos prismas.

\section{REFERÊNCIAS}

AGNOLIN, A. História das religiões: perspectiva histórico-comparativa. São Paulo: Paulinas, 2013. - (Coleção repensando a religião) 
CASTRO, F. Consequências morais do conceito de má-fé em Jean-Paul Sartre. 2005. 242f. Dissertação (Mestrado em Filosofia). Universidade Católica do Rio Grande do Sul, Porto Alegre, 2005.

DESCARTES, R. Meditações In: Descartes. Tradução de J. Guinsburg e Bento Prado Júnior. São Paulo: Abril Cultural, 1983. (Os pensadores)

HEIDEGGER, M. Ser e Tempo. Tradução Márcia Sá Cavalcanti Schubarck. Petrópolis: Vozes, 2005.

HUME, D. História natural da religião. Tradução de Jaimir Conte. São Paulo: Editora UNESP, 2005,

HUSSERL, E. Idéias para uma fenomenologia pura e para uma filosofia fenomenológica. Tradução de Márcio Suzuki. Aparecida: Idéias\&letras, 2006.

JÚNIOR, B. O circuito da ipseidade e seu lugar em “O ser e o Nada”. Doispontos, Curitiba, vol. 3, $\mathrm{n}^{\circ}$ 2, p. 29-36, Out/2006.

KANT, E. Crítica da Razão Pura. Tradução de Manuela Pinto do Santos e Alexandre Fradique Morujão $5^{\circ}$ ed. Lisboa: Fundação Calouste Gulbenkian, 2001.

MASSENZIO, M. A história das religiões na cultura moderna. Tradução de Camila Kintzel. São Paulo: Hedra, 2005.

MÜLlER, M. Sartre e a crise do fundamento. Doispontos. Curitiba, vol. 3, $\mathrm{n}^{\mathrm{o}}$ 2, p. 11-28, Out/2006.

2005.

Situações I - críticas literárias. Tradução de Cristina Prado. São Paulo: Cosac Naify,

A transcendência do Ego seguido de Consciência de si e Conhecimento de Si. Tradução de Pedro M. S. Alves. Lisboa: Edições Colibri, 1994.

OLIVEIRA, P. A religião para além da contingência humana em Jean-Paul Sartre. FAPAM, Pará de Minas, v.4, n.4 p. 52-64, Abr/2013.

OLIVEIRA, K. (Org). Ensaios de Fenomenologia e Hermenêutica da Religião. João Pessoa: Ideia, 2015.

OTTO, R. O Sagrado. São Leopoldo/Petrópolis. EST/Sinodal/Vozes. 2007.

PETTAZONI, R. L’onniscienza di Dio. Turim, 1955.

SARTRE, J. O ser e o nada - Ensaio de ontologia fenomenológica. Tradução de Paulo Perdigão. 19 ed. Petrópolis: Vozes, 2011.

Vozes, 2012.

. O existencialismo é um humanismo. Tradução de João Batista Kreuch. Petrópolis: 
SASS, S. O problema da totalidade na ontologia de Jean-Paul Sartre. 2002. 239f. Tese (Doutorado em Filosofia). Universidade Estadual de Campinas - UNICAMP. Campinas, 2002.

SILVA, E. Entre religião, cultura e história: a escola italiana das religiões. Revista de C. Humanas, Viçosa, v. 2, n 2, p. 225-234, jul./dez. 2011.

SILVA, M. A intencionalidade da consciência em Husserl. Argumentos, Fortaleza, vol. 1, p. 4553, Dez/ 2009.

VELASCO, J. Introducción a la fenomenologia de la religion. Cristiandad, 1978.

YAZBEK, A. A “desorganização interna” do Ser e o surgimento da “realidade humana” em O Ser e o Nada. Doispontos, Curitiba, vol. 3, n. 2, p. 37-51, Out/2006.

ZITKOSKI, J. O método fenomenológico de Husserl. Porto Alegre: EDIPUCRS, 1994. 